\title{
Building Environment Monitoring System based on BIM
}

\author{
Lï JiuYi* \\ Information and Control Engineering Academy, \\ Shenyang Jianzhu University \\ Shen Yang, China \\ e-mail: arnold0110@sina.com \\ * Corresponding Author \\ Wang Xin \\ School of Information \& Control Engineering \\ Shenyang Jianzhu University \\ Shenyang, China \\ Kan Fenglong \\ School of Information \& Control Engineering \\ Shenyang Jianzhu University \\ Shenyang, China \\ Zhang Dongwei \\ School of Information \& Control Engineering \\ Shenyang Jianzhu University \\ Shenyang, China
}

\author{
Liu Chunguang \\ Editorial Department of Journal \\ Shenyang Jianzhu University \\ Shenyang, China \\ Qi Ning \\ Library \\ Shenyang Jianzhu University \\ Shenyang, China \\ Kan Hongliang \\ School of Information \& Control Engineering \\ Shenyang Jianzhu University \\ Shenyang, China \\ Wang Bin \\ Northeastern University at Qinhuangdao \\ Qinhuangdao, China
}

\begin{abstract}
This paper analyzes the present situation of environmental problems in China, starting from the idea of building green building, using wireless sensor networks, established a building environment monitoring system based on BIM. The system can monitor the indoor air quality, indoor temperature, illumination time and so on, and control of temperature in the interior of the building, and set the operating state of the air conditioning system, and analysis of sunshine hours, and establish rational control strategy. The System can control the construction of the internal environment of the parameters to meet the standard of green building, the establishment of intelligent, energy conservation, harmonious living environment. The practice has proved that the system can be used in the actual application of the BIM monitoring platform for the building of the indoor environmental quality monitoring and management. This verifies that BIM technology plays an active and effective role in the green building.
\end{abstract}

Keywords- green building ; wsn; energy conservation ; BIM; Environmental monitoring

\section{INTRODUCTION}

In recent years, with the development of the times, economic progress, environmental problems become increasingly serious. As a pillar industry of our country, the construction industry is a high consumption rate, low utilization rate of the industry. How to deal with the relationship between economic development and environmental protection is an urgent problem to be solved in construction industry. BIM technology is a kind of data tool used in engineering design and construction management, which integrate the related information of various projects through the parameter model, and share and transfer in the whole life cycle of project planning, operation and maintenance, so that engineering and technical personnel to all kinds of building information to make a correct understanding and effective response. BIM technology provides the basis for the construction of the design team and the construction of various parties including the construction operation unit, to improve the production efficiency, save energy and play an important role ${ }^{[1-5]}$.

In this paper, a wireless sensor network monitoring node is used to monitor the internal data of building environment. The BIM system is established by using the data of node monitoring. The system can detect the internal temperature, air quality, illumination time and other parameters in real time, and can control the parameters of the building environment, so that it can meet the standard of green building, improve the utilization efficiency of energy, and establish a good living environment.

\section{SYSTEM HARDWARE DESIGN}

The system design ideas is to monitor temperature , visible light sensor and carbon dioxide sensors nodes by internal control node of in greenhouse, and then transmitted to the wireless gateway through the wireless network transmission to the wireless gateway, wireless gateway by post processing and computational 
preliminary to PC. The further processing and analyzing of data is in the host computer system. $t$ design throughout the whole process of professional learning, in the knowledge of learning and application form a positive interaction. The system frame diagram is shown in Fig .1.

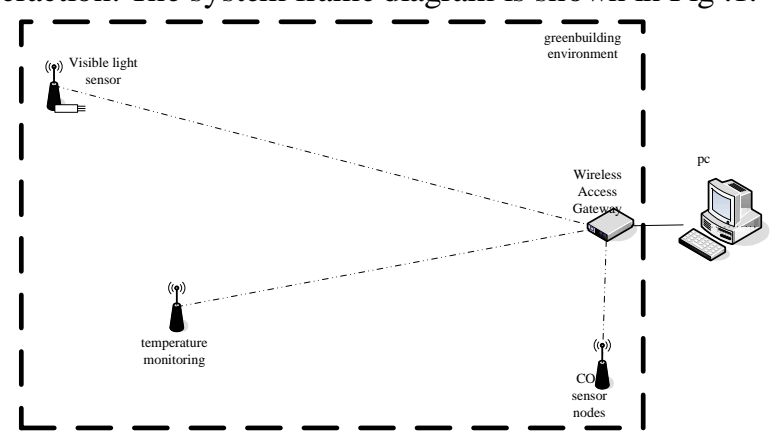

Figure 1. System frame diagram

The control system is mainly composed of three functional modules: (1) monitoring module and communicate on function of the environment (i.e., the monitoring nodes); (2) environmental information analysis, storage, control judgment function modules (i.e. wireless gateway) (3) information gathering module (i.e., PC).

\section{A. The computer system software}

This system uses visual $\mathrm{C}++6.0$ as a host computer interface program development environment; development language is $\mathrm{C}++$, using Microsoft Access database. When the wireless environment monitoring node of the data through the wireless sensor network and transmitted to the PC, PC will be in accordance with the internal procedures to receive the data stored in the database, so that the analysis and processing of data. The PC management software includes two modules: a module used to receive through the wireless sensor network data stored in the temporary variables; another module is used to analyze the data processing, the control decision is made, and will save useful data obtained from the data base.

\section{B. Wireless gateway design}

WIAPA-GW1498 wireless gateway is mainly responsible for the configuration and management of the entire wireless sensor network, its core is composed of AT91RM9200, Data Flash, 128Mb, SDRAM extended $32 \mathrm{Mb}$ and 4MSRAM.WIAPA-GW1498 wireless gateway consists of WIAPA-M1800, industrial 485 communication interface, RS232 communication interface, adaptive 10M/100M Ethernet interface. The host computer can be transmitted through configuration, commands and data to the WIAPA-GW1498 wireless gateway serial or Ethernet interface, the system hardware frame diagram as shown in Fig.2.

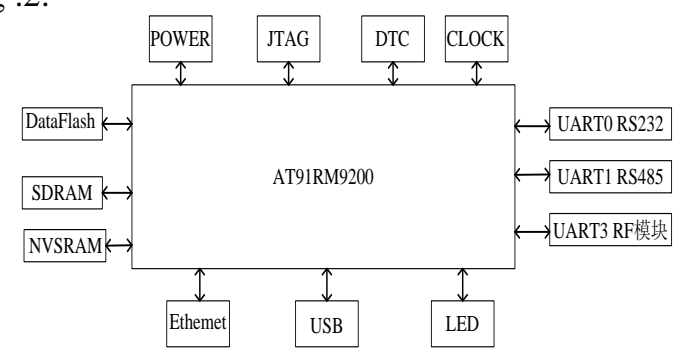

Figure 2. The system hardware frame diagram

\section{The design of monitoring node}

The design idea of this node is used MSP430F1611 microcontroller as the nodes of the micro controller; the chip of CC2420 is used as the wireless communication chip, the two through control bus and data bus for effective electrical connection, according to the application and the required function of different choice of access sensor.

1) $\mathrm{CC} 2420$

CC2420 is TI introduced the first meets $2.4 \mathrm{GHz}$ IEEE 802.15.4 standards of RF transceiver. The CC2420 function is very powerful, the device is based on TI Smart technology and made the $0.18 \mathrm{~m}$ CMOS, the process of making it in the performance is very stable and low power consumption. The RF device integrated voltage controlled oscillator and crystal oscillator with the use of $16 \mathrm{MHz}$ and other peripheral circuits, antennas, to facilitate the work in $2.4 \mathrm{GHZ}$ band. Each index of the device has reached IEEE 802.15.4 standard requirements, to ensure reliable and efficient transmission of signal in wireless sensor networks [6-7].

\section{2) Temperature monitoring node}

The temperature sensor was designed by using the DS18B20 chip produced by DALLAS Company in USA. The chip is a 1-wire digital temperature sensor, the device within the integrated temperature sensor, data conversion chip, a memory chip and computer interface chip with various functions module, the device temperature signal can be converted into a 16 bit serial digital signal, and through the serial output mode and micro controller to communicate. Temperature range of -55 to $+125 \mathrm{C}$, programmable resolution is $9 \sim 12$, the corresponding resolvable temperature were $0.5 \mathrm{C}, 0.25 \mathrm{C}, 0.125 \mathrm{C}$ and $0.0625 \mathrm{C}$, can achieve high measurement accuracy. The applicable voltage range of $3.0 \sim 5.5 \mathrm{~V}$, the working voltage can be provided using remote introduced, can also use the parasitic power supply mode. In order to save the resources of the microcontroller, can put a plurality of DS18B20 chip by parallel connection, the micro controller using a root port line can measure multi-point temperature of the air, avoid micro controller hardware resources waste. The above characteristics make the chip is very suitable for multi point temperature monitoring system.

3) Visible light sensor

The visible light sensor was designed by using the S1087 chip produced by Hamamat Company in Japan. The following are working parameters:

TABLE I. WORKING PARAMETERS OF VISIBLE LIGHT

\begin{tabular}{|l|c|}
\hline \multicolumn{1}{|c|}{ Basic parameters } & variation range \\
\hline Operating voltage range & $2.4--12 \mathrm{v}$ \\
\hline Working temperature range & -20 to $+75 \mathrm{C}$ \\
\hline Storage temperature & -40 to $+120 \mathrm{C}$ \\
\hline Welding temperature & $260 \mathrm{C}$ \\
\hline
\end{tabular}

The dark current is small, low illumination response, high sensitivity, and the current increases with the increase of light intensity. Built in UNIKA sense source, automatic attenuation of near infrared, spectral response is close to 
the human eye function curve. It is built in micro signal CMOS amplifier, high precision voltage source and correction circuit, output current, wide operating voltage range, good temperature stability. It is used Optical nano material package, visible light transmittance, ultraviolet cut-off, near infrared relative attenuation, enhanced optical filter effect.

\section{4) Carbon dioxide sensors}

The carbon dioxide sensors were designed by using the TGS4160 chip produced by FIGARO Company in Japan. The following are working parameters:

- Measurement range: 300-5000ppm

- Accuracy: $20 \%$

- Power consumption: $13 \mathrm{~W}$

The main features of the long service life, maintenance free, wide detection range, the $\mathrm{CO}_{2}$ has a high sensitivity of carbon dioxide

\section{BUILDING INFORMATION MODEL MANAGEMENT STRATEGY}

\section{A. BIM model integration}

BIM's 3D model is not simply integrated digital information, it is the digital information applied to the design, construction, management of visualization, digital, collaborative and sharing method. By Revit, ArchiCAD and other three-dimensional systems and software combined, in the past, the need to spend a long time to resolve the model, and now can be completed by the software simple and rapid. Among them, the designer for the project design, construction and operation of the process to achieve the visualization of the results, to facilitate effective communication, discussion and decision-making, and to give scientific quantitative analysis ${ }^{[8-10]}$.

\section{B. Dynamic management of BIM}

BIM is not a separate 3D model, which can be integrated into the 4D control system. After the construction of the building is completed, according to the construction of the organization the system designed simulation of the actual construction site monitoring. So as to determine the reasonable construction plan to guide the construction, to avoid the problem, improve the work efficiency, and fully protect the green building design process of scientific and reasonable.

\section{Research methods of BIM in environmental monitoring of green building}

\section{1)Design analysis and construction optimization \\ a)Temperature index control}

Through the building model of BIM, the analysis software of Ecotect is introduced and the local meteorological data is loaded into the whole building and the simulation study is made, and the temperature, the indoor temperature and the average radiation of the surrounding objects are analyzed. By properly adjusting the material and equipment, both to achieve indoor comfort, but also to a certain extent, reduce indoor dust and inhibit bacterial growth

\section{b) Building ventilation}

The design of the green building, with special emphasis on natural ventilation, not only shortens the operation time of air conditioning equipment, but also helps to reduce the energy consumption of air conditioning. This requires a detailed understanding of the location and relative direction of the wind, and the design of the correct building ventilation system is obtained. By BIM visualization simulation of the local wind direction and wind speed, the design process can be direction and the window size is by adjusting the doors and windows to deal with the location and size of the vents, and change air vent layout to improve indoor air flow distribution and guide indoor airflow organization effective ventilation, make turbid gas discharge quickly.

c)Sunshine analysis

Building to accept the illuminating surface of a window of the location, size, and type, influences the indoor environment, including the use of materials and furniture decoration。

For example in the hot summer, in order to prevent the sun and reduce the excessive heat into the interior, causing heavy volume of furniture and materials. Through the visible light sensor node to monitor the time and the radiation level, set the reasonable size, the form of the sun's reflection of the sun. Of course, this example should be taken into account the building energy consumption, indoor comfort and other factors, and to find a proper balance point.

\section{2) Dynamic monitoring system}

BIM environmental monitoring system through the indoor environment monitoring node of the building's indoor air quality monitoring and timely regulation, Including the concentration of indoor air pollutants monitoring, tracking and monitoring, detection of information feedback and alarm and control system, control indoor air pollution levels.

The system can automatically detect the main function room. Because of the changes in the environment and the indoor personnel, the indoor temperature has been changed, and the content of carbon dioxide and air pollutants can also be increased. First of all, the use of computers is to the indoor environment parameters and set the threshold. Then the data collection of the carbon dioxide concentration in the indoor air environment and the concentration of pollutants in the air is collected by the sensor. Then by wireless sensor network node, the collected information index is transferred to the BIM monitoring platform, and the data storage, statistics and analysis are carried out, and compared with the setting parameter values.

For example, when the concentration of carbon dioxide and air pollutant concentrations exceed the standard or not in the scope of the set, the system can realize real-time automatic warning to the relevant work management personnel, control personnel to detect the working status of ventilation equipment, as well as indoor air pollution monitoring system of the degree of association, and achieve the purpose of automatic ventilation and temperature regulation of the system. Because of the different geographical environment, the building needs to adjust according to different information in the actual process of optimization, so as to improve the overall environment quality of buildings. 


\section{CONCLUSION}

At present, with the help of BIM technology in China has just started. BIM technology is in a stage of rapid development. This paper establishes a building environment monitoring system. The practice shows that the system can monitor the indoor air quality, monitor the indoor temperature and light conditions. And according to the control strategy, the above parameters are controlled. It has a wider significance for building operations, maintenance and other processes. It greatly improves the utilization of building energy, built a good living environment, and achieved the purpose of building green building.

However, the relationship between human and architecture and environment is excavated from the deep level. For realized the green building requirements, we need to continue to explore. We should believe that in the near future, the technology of building design will be more and more perfect by using BIM. We are able to achieve a harmonious living environment, which is in line with the functional requirements of the living material, but also in line with health requirements

\section{REFERENCES}

[1] Zhang J P, "Research and applicationg of BIM technology,"Construction Technology,Feb.2011, pp. 117-118
[2] EASTMAN Cetal, BIM Handbook:A Guide to Information Modeling for Owners,Managers,Designers,Engineers and Contractors,1st ed.,New York:John Wiley and Sons, 2008, pp.6873

[3] Yin K,Wang X P,Liu X W,Hu Z Z, "Research on mechanical and electrical equipment management system based on BIM". Construction technology, Oct.2013, pp. 87-88

[4] Guo J,Zhang Y, "Research on building space and equipment operation and maintenance management system based on BIM" Journal of Information Technology in Civil Engineering and Architecture, Mar.2013, pp. 42-43

[5] Wang Xin,Guo Lili,Ma Lina. Cooperative Spectrum Sensing Algorithm Based on Second User Selection and Random Forest Classification[J].ICIC Express Letters, Part B: Applications,2015, $6(3): 845-850$.

[6] Zhang M J,Meng X N,Wang C B,Xiao X, “Application of ZigBee wireless technology in roof pressure monitorning". Journal of Liaoning Technical University, Dec.2014, pp. 1667-1668

[7] Yick Jennifer,Mukherjee Biswanath,Ghosal Dipak, "Wireless sensor network survey". Computer Net-works, 2008, pp. 302-303

[8] Wang Z J, “Application of BIM technology in building operation and maintenance management". Building economy, Sep.2013, pp. 96-97

[9] Wang Xin, Huang Kuan, Gao Zhijun. The Primary Users' Signals Recognition Algorithm in Cognitive Radio Networks via KPCA and Random Forest[J].ICIC Express Letters,2015, 9(4):1083-1088.

[10] Ge W L, Yu X M, He B, The second dimension of BIM:Different participants in the BIM project application, 1st ed.,Beijing:China Architecture\&Building Press, 2011, pp.68-73. 